University of Nebraska - Lincoln

DigitalCommons@University of Nebraska - Lincoln

Biological Systems Engineering: Papers and

Publications

Biological Systems Engineering

6-1994

\title{
Maximum Surface Storage Provided by Crop Residue
}

John E. Gilley

University of Nebraska-Lincoln, john.gilley@ars.usda.gov

Eugene R. Kottwitz

University of Nebraska-Lincoln

Follow this and additional works at: https://digitalcommons.unl.edu/biosysengfacpub

Part of the Biological Engineering Commons

Gilley, John E. and Kottwitz, Eugene R., "Maximum Surface Storage Provided by Crop Residue" (1994). Biological Systems Engineering: Papers and Publications. 71.

https://digitalcommons.unl.edu/biosysengfacpub/71

This Article is brought to you for free and open access by the Biological Systems Engineering at DigitalCommons@University of Nebraska - Lincoln. It has been accepted for inclusion in Biological Systems Engineering: Papers and Publications by an authorized administrator of DigitalCommons@University of Nebraska Lincoln. 


\title{
Maximum Surface Storage Provided by Crop Residue
}

\author{
By John E. Gilley' and Eugene R. Kottwitz ${ }^{2}$
}

\begin{abstract}
Small ponds created by crop residue serve to store water on upland areas. The present study is conducted to identify the maximum surface storage provided by crop residue. Equations for estimating surface storage are derived assuming that residue elements were oriented end to end, at uniform intervals, in a direction perpendicular to flow. Separate equations are developed for conditions where average slope was greater than or equal to residue cover, or less than residue cover. Both equations relate average surface-storage depth to residue cover, residue diameter, and average slope. Data to test the reliability of the equations are obtained in a laboratory investigation. Artificial residue elements are glued onto a 1$\mathrm{m}^{2}$ test section positioned at slopes of $1 \%, 10 \%$, or $20 \%$. Four sizes of residue elements and three surface-cover conditions are examined. Surface-storage depth for each experimental condition is measured. Close agreement is found between predicted and measured surface-storage values. Surface storage occurring under field conditions may be substantially less than the estimates obtained using the predictive equations.
\end{abstract}

\section{INTRODUCTION}

The relatively large energy requirements for center-pivot irrigation systems has created interest in reducing the operating pressure of these systems (Gilley 1984). Low-energy, precision application (LEPA) systems have been developed that distribute water to the soil surface at very low pressure through drop tubes and orifice-controlled emitters (Lyle and Bordovsky 1981). LEPA systems apply water at much higher intensities than conventional center-pivot irrigation systems, increasing the potential for significant amounts of runoff. Runoff from LEPA systems can be reduced if sufficient surface storage is available. Surface storage can be provided by tillageinduced depressional storage, microbasin land preparation, and crop residue.

Tillage-induced depressional storage can be characterized using random roughness. A procedure developed by Allmaras et al. (1967) uses height measurements for calculating random roughness. The effects of slope and oriented tillage tool marks are mathematically removed to reduce the variation among measurements.

Zobeck and Onstad (1987) reviewed the available literature to identify random-roughness values for selected tillage operations. The addition of rainfall or irrigation may serve to reduce random roughness. Equations for quantifying the reduction in random roughness from information on $\mathrm{cu}-$ mulative rainfall since the last tillage operation were derived by Zobeck and Onstad (1987). Onstad (1984) in turn developed equations relating tillage-induced depressional storage to random roughness and slope steep-

\footnotetext{
${ }^{1}$ Agric. Engr., USDA-ARS, Univ. of Nebraska, Lincoln, NE 68583-0934. NE.

${ }^{2}$ Res. Engr., Dept. of Biological Systems Engrg., Univ. of Nebraska, Lincoln,

Note. Discussion open until September 1, 1994. To extend the closing date one month, a written request must be filed with the ASCE Manager of Journals. The manuscript for this paper was submitted for review and possible publication on May 26, 1993. This paper is part of the Journal of Irrigation and Drainage Engineering, Vol. 120, No. 2, March/April, 1994. CASCE, ISSN 0733-9437/94/0002-0440/\$2.00 $+\$ .25$ per page. Paper No. 6248 .
} 


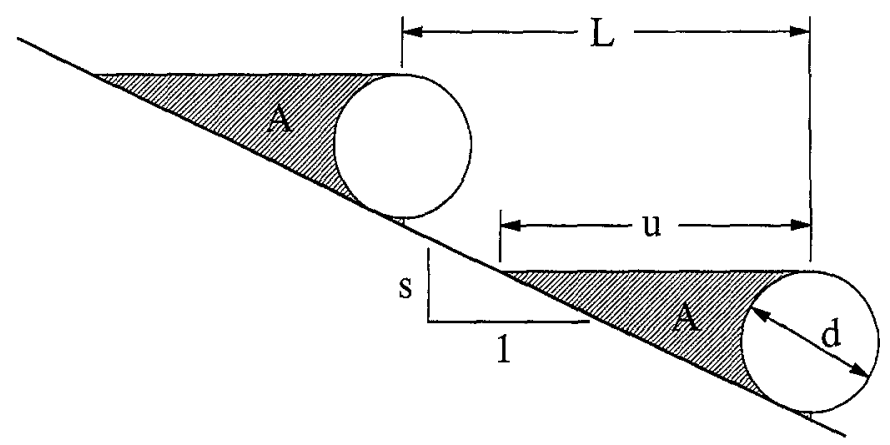

FIG. 1. Surface Storage for Case I; Slope Gradient $\geq$ Surface Cover

ness. Soil-surface storage values for various slopes have also been reported by Dillon et al. (1972).

Microbasin land preparation results in mounds of soil being mechanically placed at selected intervals along a furrow to form small reservoirs (Lyle and Dixon 1977). Use of basin tillage for water storage may be necessary on many sites using LEPA systems. Much larger surface-storage volumes are provided by basin tillage than are available from tillage-induced depressional storage or crop residues.

Small ponds can be created by crop residue (Brenneman and Laflen 1982). The cumulative volume generated by a large number of ponds can be substantial, even though the amount of water stored in individual ponds may be small. The objective of the present study is to identify maximum surface storage provided by crop residue.

\section{SURFACE-STORAGE EQUATIONS}

To solve many engineering problems, the upper and lower limits of selected parameters must be identified. Surface storage by crop residue is substantially influenced by the orientation of the residue elements with respect to the direction of flow. The maximum amount of surface storage results when residue elements are oriented perpendicular to flow. The present study focuses primarily on deriving and testing equations for this maximum surface-storage condition.

\section{Basic Concepts}

In developing equations to estimate maximum surface storage, it is assumed that each of the residue elements is oriented perpendicular to the direction of flow. The residue elements are also assumed to be placed end to end. Finally, the spacing between rows of residue elements is assumed to be uniform.

Fig. 1 shows that the horizontal distance the reservoir extends upslope $u$ is given as

$$
u=d / s
$$

where $d=$ residue diameter; and $s=$ average slope given as a fraction. Residue cover $c$ expressed as a fraction is estimated from the equation

$$
c=\frac{d w}{L w}
$$


where $w=$ representative length of a residue element; and $L=$ residue spacing. Rearranging (2) yields

$$
L=d / c
$$

and for the condition represented in Fig. 1

$$
L \geq u
$$

Substituting (1) and (3) into (4) yields

$$
d / c \geq d / s
$$

Simplifying (5) produces

$$
s \geq c
$$

Eq. (6) is evaluated as case I. Case II is represented by the condition

$$
s<c
$$

Case I. $s \geq c$

Fig. 1 shows that cross-sectional storage area $A$ is given as

$$
A=\frac{d u}{2}-\frac{\pi d^{2}}{8}
$$

Average surface-storage depth $y$ is represented as

$$
y=A / L
$$

Substituting (1), (3), and (8) into (9) and simplifying yields

$$
y=c d\left(\frac{1}{2 s}-\frac{\pi}{8}\right)
$$

Case II. $s<c$

The situation represented by case II is shown in Fig. 2. For this condition, $A$ is given by

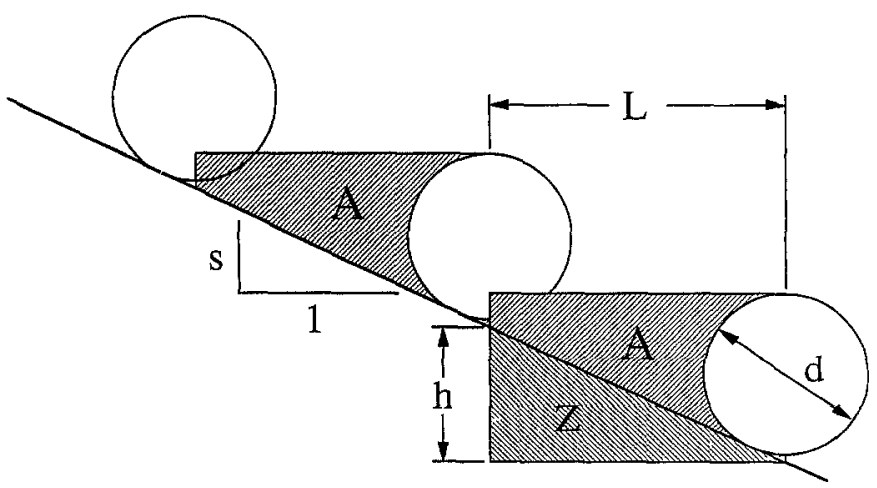

FIG. 2. Surface Storage for Case II; Slope Gradient $<$ Surface Cover 


$$
A=d L-Z-\frac{\pi d^{2}}{8}
$$

where $Z=$ cross-sectional area of height $h$, which is used to calculate storage area. $Z$ is represented as

$$
Z=h L / 2
$$

Fig. 2 shows that the downslope residue element reduces $A$. This reduction is represented as the last term in (11). A much smaller decrease in $A$ is caused by the upslope residue element. This decrease in storage area is assumed to be negligible.

For the situation shown in Fig. 2

$$
s=h / L
$$

Substituting (12) and (13) into (11) and simplifying yields

$$
A=d L-\frac{s L^{2}}{2}-\frac{\pi d^{2}}{8}
$$

Finally, using (3) and (9)

$$
y=d\left(1-\frac{s}{2 c}-\frac{\pi c}{8}\right)
$$

Eqs. (10) and (15) both relate average surface-storage depth to residue cover, residue diameter, and average slope. These three independent variables can be measured or estimated for most field conditions.

\section{EXPERIMENTAL PROCEDURES}

A laboratory study was conducted to test the reliability of the equations developed in the previous section. Copper tubing (with $0.953-$ and $1.27-\mathrm{cm}$ outside diameters) and polyvinyl chloride (PVC) pipe (2.15- and 2.67-cm outside diameter) were used to simulate residue materials. These cylindrical elements were selected, since they do not absorb water. Surface-cover values corresponding with each of the simulated residue elements are shown in Table 1. By knowing the total number of rows of residue elements in each test and residue diameter, surface-cover values were calculated.

Tests were conducted using a specially fabricated plywood table having

TABLE 1. Experimental Surface-Cover Values for Selected Residue Elements

\begin{tabular}{c|c|c|c}
\hline \hline $\begin{array}{c}\text { Residue diameter } \\
(\mathrm{cm})\end{array}$ & \multicolumn{3}{|c}{$\begin{array}{c}\text { Surface cover } \\
\text { (percent) }\end{array}$} \\
\cline { 2 - 4 }$(1)$ & $(2)$ & $(3)$ & $(4)$ \\
\hline 0.953 & 9.53 & 19.1 & 38.1 \\
1.27 & 8.89 & 17.8 & 35.6 \\
2.15 & 8.58 & 17.2 & 34.3 \\
2.67 & 8.00 & 16.0 & 32.0 \\
\hline
\end{tabular}

Note: For each residue diameter, three surface-cover conditions were evaluated. Surface-storage measurements, in turn, were obtained at slopes of $1 \%, 10 \%$, and $20 \%$ for each surface-cover condition. 
dimensions of $1.22 \mathrm{~m}$ by $2.44 \mathrm{~m}$. The top of the table was covered with a smooth fiberglass sheet. A $1-\mathrm{m}^{2}$ area near the center of the table was used for testing. Wooden boards that diverted excess water to a collection channel at the bottom of the table served as a border on two sides of the test area. A jack allowed the table to be adjusted to the desired slope gradient.

Simulated residue elements were placed along the top and bottom of the test area, perpendicular to the slope. Additional residue elements were located at uniform intervals within the test section. For a given residue diameter, surface-cover values were increased by placing additional rows of residue elements within the test section. This was accomplished by doubling the number of rows of residue elements within the test section while still maintaining a uniform spacing between residue elements. The copper tubing and PVC pipe were placed in contact with the side borders. Thus, water was not allowed to drain around the ends of the residue elements.

Analyses of the storage equations showed that the greatest increase in surface storage generally occurs for small values of residue cover. For very large surface-cover conditions, much of the effective storage volume is occupied by crop materials. Therefore, surface-cover values ranging from approximately $8 \%$ to $38 \%$ were evaluated in the present study.

The laboratory experiment was designed to provide a sufficient number of measurements to adequately test (10) and (15). A slope gradient of $1 \%$ appeared to be a reasonable lower limit that could be easily accommodated using the existing experimental equipment. The $20 \%$ slope was arbitrarily selected as an upper limit, and the $10 \%$ slope gradient served as an intermediate value.

The approximate quantity of water to be added to the test section was first identified from the surface-storage equations. Water was progressively added to the test section from the upslope to the downslope direction. Surface storage provided by an upslope residue element was first satisfied before water was added to the next residue element. The volume of water that ran over the bottom residue element was subtracted from the total amount of water added to the test section to obtain the volume of water that was stored.

Two measurements of surface storage were made for each experimental treatment. For a given residue-element size and surface-cover value, surface storage for the three experimental slope gradients were determined. Surface cover was then doubled and the next series of measurements were made.

\section{RESULTS}

Measured and predicted surface-storage depths at varying residue cover for residue elements with a $2.67-\mathrm{cm}$ diameter are shown in Fig. 3 . The trends presented in Fig. 3 are also characteristic of the other residue-element sizes. Residue diameter serves as an upper limit for average surface-storage depth. Thus, maximum surface storage for a $2.67-\mathrm{cm}$ diameter residue element would be somewhat less than $2.67 \mathrm{~cm}$. Fig. 3 shows that for a given residue cover, surface-storage depth is reduced as slope gradient becomes larger. The reduction in surface storage with slope gradient is less pronounced for larger residue-cover values.

Measured surface-storage depths at the 1\% slope gradient decreased with residue cover. The condition where slope gradient is less than surface cover is illustrated in Fig. 2. On very flat surfaces, the principal effect of increased surface cover is to reduce effective cross-sectional storage area.

For slopes with gradients of $10 \%$ and $20 \%$, surface-storage depths con- 


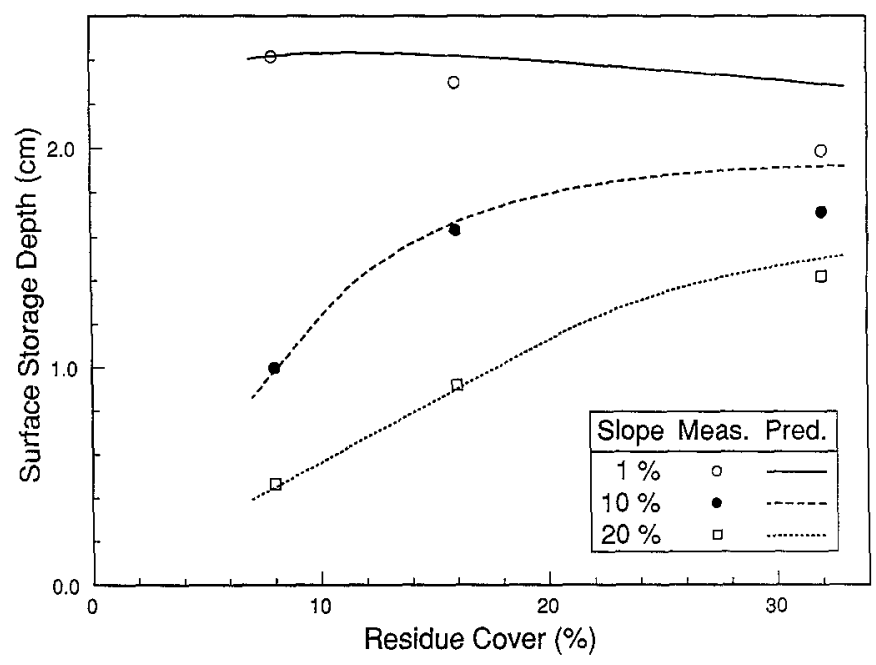

FIG. 3. Surface-Storage Depth versus Residue Cover for $2.67-\mathrm{cm}$-Diameter Residue Elements

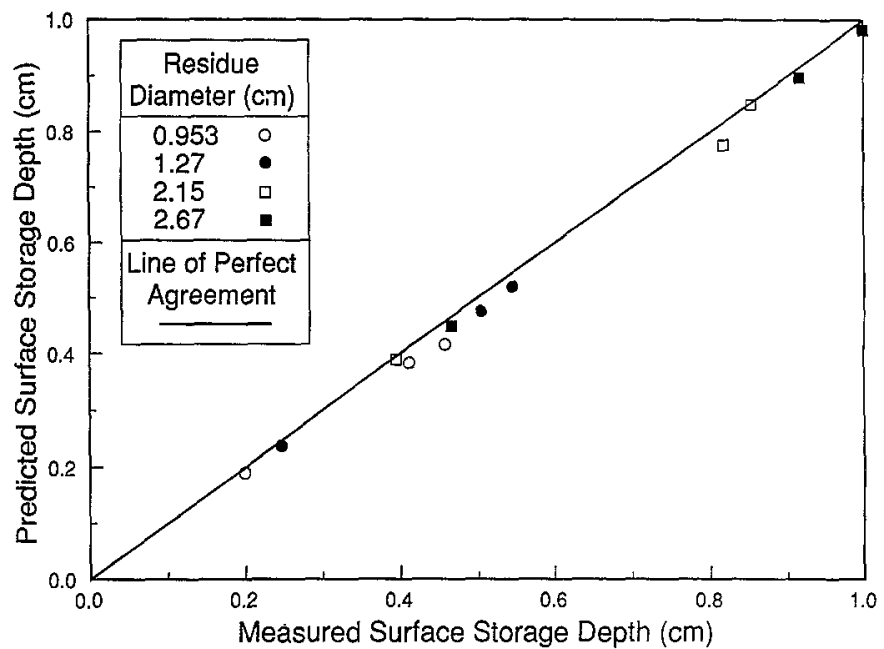

FIG. 4. Predicted versus Measured Surface-Storage Depth for Case I; Slope Gradient $\geq$ Surface Cover

sistently increased with greater residue cover. Slope gradients for these test series were in some cases larger than surface cover, and in other cases less than surface cover. On these steeper slopes, increased surface cover provided additional storage reservoirs, and thus greater effective cross-sectional storage area.

\section{TESTING OF SURFACE-STORAGE EQUATIONS}

Predicted versus measured surface-storage values for case I are presented in Fig. 4. Close agreement was found between predicted and measured 
storage depths. Measured surface storage was slightly larger than predicted values for each of the individual tests.

Fig. 5 shows predicted versus measured surface storage for case II. Again, predicted and measured storage depths were similar. For most of the individual tests, predicted surface storage was slightly larger than measured values. Fig. 2 shows that the upslope residue element may slightly reduce the cross-sectional storage area provided by the down-slope residue element. This small reduction in storage depth is not considered in (15). Thus, predicted storage depths obtained using (15) may be slightly larger than measured values.

Linear regression analyses were used to compare predicted and measured surface-storage values. Results of the statistical analyses are shown in Table 2. Coefficient of determination values of 0.998 and 0.979 were found for the data presented in Figs. 4 and 5, respectively.

The Students $t$-test was used to evaluate the hypotheses that the regression coefficients shown in Table 2 equal unity and that the intercepts equal zero at the $95 \%$ confidence level. The slopes were not significantly different from

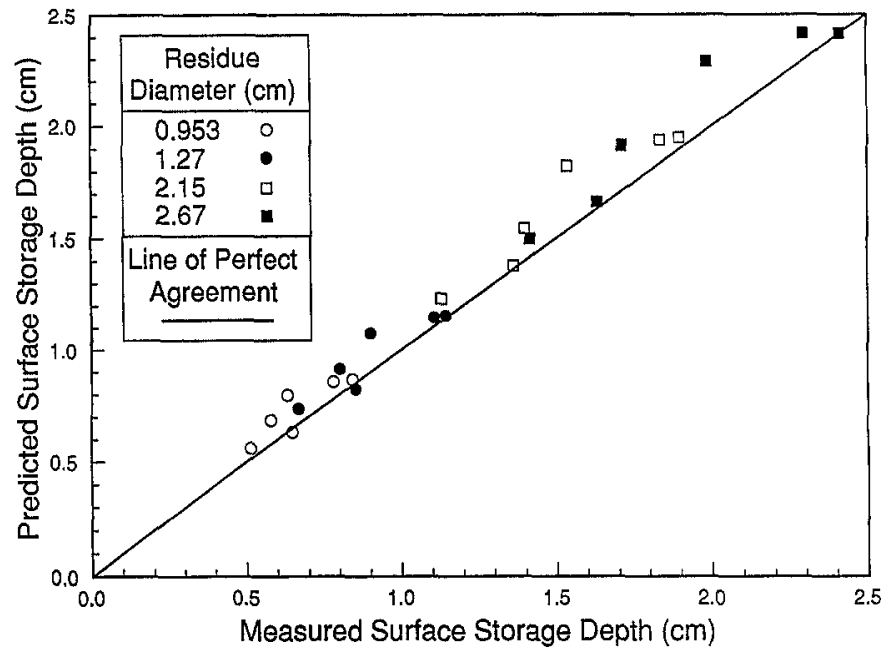

FIG. 5. Predicted versus Measured Surface-Storage Depth for Case II; Slope Gradient $<$ Surface Cover

TABLE 2. Statistical Analyses of Predicted versus Measured Surface-Storage Depth

\begin{tabular}{|c|c|c|c|c|c|c|}
\hline \multirow[b]{2}{*}{$\begin{array}{l}\text { Regression } \\
\text { equation } \\
\text { (1) }\end{array}$} & \multirow{2}{*}{$\begin{array}{c}\text { Coefficient of } \\
\text { determination } \\
r^{2} \\
(2)\end{array}$} & \multirow[b]{2}{*}{$\begin{array}{c}F \\
(3)\end{array}$} & \multicolumn{2}{|c|}{$\beta_{1}$} & \multicolumn{2}{|c|}{$\beta_{0}$} \\
\hline & & & $\begin{array}{c}\text { Students- } \\
t \\
(4)\end{array}$ & $\begin{array}{c}\text { Standard } \\
\text { error } \\
\text { (5) }\end{array}$ & $\begin{array}{c}\text { Students- } \\
t \\
(6)\end{array}$ & $\begin{array}{c}\text { Standard } \\
\text { error } \\
\text { (7) }\end{array}$ \\
\hline \multicolumn{7}{|c|}{ (a) Slope Gradient $\geq$ Surface Cover } \\
\hline$\hat{y}=0.995 y-0.017$ & 0.998 & 4,350 & -0.337 & 0.015 & -1.85 & 0.094 \\
\hline \multicolumn{7}{|c|}{ (b) Slope Gradient $<$ Surface Cover } \\
\hline$\hat{y}=1.04 y+0.048$ & 0.979 & 1,040 & 1.12 & 0.032 & 1.08 & 0.440 \\
\hline
\end{tabular}


unity, nor were the intercepts significantly different from zero. Thus, analyses of the experimental data suggest that (10) and (15) can be used to estimate surface storage.

\section{COMMENT}

Cylindrical elements having uniform diameters were used to derive the surface-storage equations. Under field conditions the size of residue materials may be widely variable. A mean value of residue diameter could be used or the amount of residue material and surface storage provided by each of several size classes could be estimated.

The amount of crop residue varies throughout the year. Tillage operations and residue decomposition may affect residue cover. Crop residue may also be removed by overland flow.

In this investigation, residue elements were placed perpendicular to the direction of flow, at uniform intervals. Under field conditions, residue elements are often oriented randomly. Surface-storage volumes would be expected to be substantially reduced for randomly oriented residue materials.

Additional laboratory tests were conducted on corn stalks that were oriented perpendicular to the direction of flow. However, the corn stalks did not extend across the entire width of the test section. As water was slowly added upslope of a residue element, a small pond formed. Once a particular storage volume had been reached, water rapidly moved around the outside edges of the residue element until almost the entire reservoir had been drained. Under field conditions, lateral movement of water around residue materials would be expected to substantially reduce effective storage volume.

Brenneman and Laflen (1982) have shown that the ponds formed upslope from residue elements can be very effective in collecting sediment. Because of their high sediment-trapping efficiency, the effective storage-volume of the reservoirs may be rapidly depleted. Thus, surface-storage measurements obtained in the present study should be considered as maximum values for single-layer residue materials.

For some crops, such as wheat, it is not uncommon for multiple layers of residue elements to be located on the soil surface. Greater residue depth could have the same effect on surface storage as increasing residue diameter. The equations derived in this study should not be applied to conditions where multiple layers of crop material are prevalent.

\section{SUMMARY AND CONCLUSIONS}

Water may be stored on upland areas in small ponds created by crop residue. The cumulative volume generated by a large number of ponds can be substantial. Maximum surface storage provided by crop residue was identified in this investigation.

Equations for estimating maximum surface-storage were derived assuming that residue elements were oriented end to end, at uniform intervals, in a direction perpendicular to flow. Separate equations were developed for conditions where average slope was greater than or equal to residue cover, or less than residue cover. Residue cover, residue diameter, and average slope were included as independent variables in both prediction equations.

A laboratory study was conducted to obtain data to test the reliability of the surface-storage equations. Copper tubing $(0.953-$ and $1.27-\mathrm{cm}$ outside diameter) and PVC pipe (2.15- and $2.67-\mathrm{cm}$ outside diameter) were used 
to simulate crop residue. The artificial residue elements were glued onto a $1-\mathrm{m}^{2}$ test section positioned at slopes of $1 \%, 10 \%$, or $20 \%$. Average surfacestorage depths for each of three surface-cover conditions were then measured.

Close agreement was found between predicted and measured storage depths for each of the individual tests. Statistical analyses indicated that no significant difference existed between predicted and measured values. Thus, the equations can be used to estimate maximum surface-storage depth.

The assumptions required to derive the surface-storage equations apply only to idealized conditions. Surface-storage depths obtained using the equations should be considered only as upper limits for single-layer residue materials. Under field conditions, surface-storage depths may be substantially less than the maximum values.

\section{ACKNOWLEDGMENT}

This paper is a contribution from the U.S. Department of AgricultureAgricultural Research Service, Lincoln, Nebraska in cooperation with the Agricultural Research Division, University of Nebraska, also in Lincoln, and is published as journal series number 10422 .

\section{APPENDIX I. REFERENCES}

Allmaras, R. R., Burwell, R. E., and Holt, R. F. (1967). "Plow-layer porosity and surface roughness from tillage as affected by initial porosity and soil moisture at tillage time."Proc., Soil Sci. Soc. Am., 31(4), 550-556.

Brenneman, L. G., and Laflen, J. M. (1982). "Modeling sediment deposition behind corn residue." Trans., ASAE, 25(5), 1245-1250.

Dillon, R. C., Hiler, E. A., and Vittetoe, G. (1972). "Center-pivot sprinkler design based on intake characteristics." Trans., ASAE, 15(5), 996-1001.

Gilley, J. R. (1984). "Suitability of reduced pressure center-pivots." J. Irrig. and Drain. Engrg., ASCE, 110(1), 22-34.

Lyle, W. M., and Bordovsky, J. P. (1981). "Low energy precision application (LEPA) irrigation system." Trans., ASAE, 24(5), 1241-1245.

Lyle, W. M., and Dixon, D. R. (1977). "Basin tillage for rainfall retention." Trans., $A S A E, 20(6), 1013-1017,1021$.

Onstad, C. A. (1984). "Depressional storage on tilled soil surfaces." Trans., ASAE, $27(3), 729-732$.

Zobeck, T. M., and Onstad, C. A. (1987). "Tillage and rainfall effects on random roughness: a review." Soil and Tillage Res., 9, 1-20.

\section{APPENDIX II. NOTATION}

The following symbols are used in this paper:

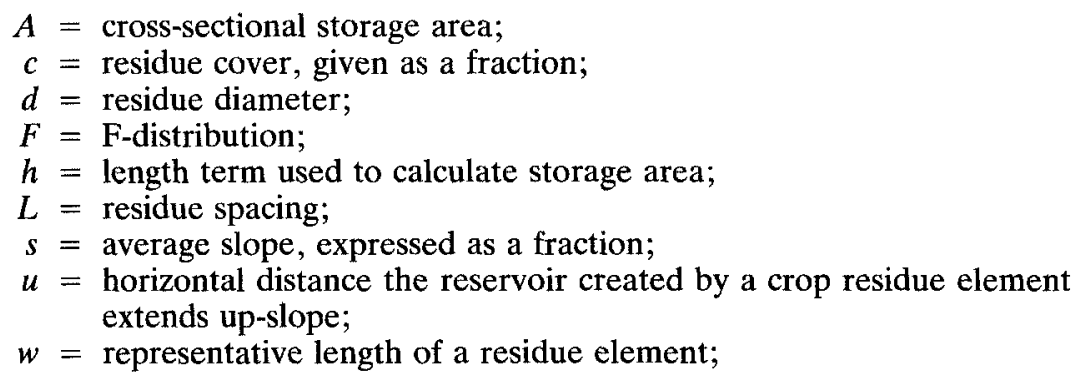


$y=$ average surface-storage depth;

$\hat{y}=$ predicted surface-storage depth;

$Z=$ cross-sectional area used to calculate storage area;

$\beta_{0}=$ intercept in regression equation; and

$\beta_{1}=$ regression coefficient in regression equation. 